\title{
Pendidikan Islam dan Konservasi Lingkungan
}

\author{
Muh. Idris ${ }^{1}$, Sabil Mokodenseho $^{2}$, Evra Willya $^{3}$, Yusno Abdullah Otta ${ }^{4}$ \\ ${ }^{1}$ Institut Agama Islam Negeri Manado, Indonesia \\ Email: idristunru02@gmail.com \\ ${ }^{2}$ Universitas Islam Negeri Syarif Hidayatullah Jakarta, Indonesia \\ Email: sabil.mokodenseho@gmail.com \\ ${ }^{3}$ Institut Agama Islam Negeri Manado, Indonesia \\ Email: evrawillya@iain-manado.ac.id \\ ${ }^{4}$ Institut Agama Islam Negeri Manado, Indonesia \\ Email: yusno.otta@iain-manado.ac.id
}

\begin{abstract}
Humans are faced with some terrible natural disasters which endanger their lives and the biosphere. These are inseparable from human activities which lead to global warming. Therefore, it takes conscious effort to carry out environmental conservation and this would be more effective when carried out by all parties. Islamic education is one of the efforts aimed at conserving the environment owing to the fact it builds awareness on its importance and is a journey pioneered for the survival of the next generation. Education helps to understand various values and concepts needed to develop the attitudes and skills towards building mutual relations between humans, culture and the environment. Through education, humans form attitudes which help to have a concern for the environment.
\end{abstract}

Keywords: Islamic education; Environmental Conservation; Value; Concept

\section{Pendahuluan}

Isu lingkungan hidup telah menyadarkan manusia tentang pentingnya keberlanjutan lingkungan untuk kesejahteraan manusia [1-2]. Isu-isu tersebut ialah pencemaran lingkungan, pemanasan global, perubahan iklim, kemerosotan keanekaragaman hayati dan sumber daya alam [3-4]. Hutan Indonesia merupakan paru-paru dunia dan salah satu dari tiga wilayah hutan yang mampu menjaga keseimbangan iklim global [5-6], selain hutan Amazon di Amerika Latin dan Kongo, Afrika [7-9]. Keberadaannya sangat penting bagi seluruh dunia.

Selama abad 20, Indonesia mengalami peningkatan suhu rata-rata udara di permukaan tanah 0,5 derajat celsius [10-11]. Jika dibandingkan periode tahun 1961 hingga 1990, rata-rata suhu di Indonesia diproyeksikan meningkat 0,8 sampai 1,0 derajat celsius antara tahun 2020 hingga 2050 [12-13]. Tutupan terumbu karang di Indonesia sepanjang 2016 mengalami penurunan jika dibandingkan dengan tahun sebelumnya [14]. Tren ini terjadi sejak 2013 dengan kecenderungan serupa terjadi di sejumlah negara lain [15]. Di Indonesia dari sekitar 2,5 juta hektar luas terumbu karang, hanya 6,39 persen berada dalam kondisi sangat baik, 23,40 persen dalam kondisi baik, 35,06 persen dalam kondisi cukup dan 35,15 persen dalam kondisi jelek [16-17]. Dampak lain dari perubahan iklim adalah sering terjadinya kebakaran hutan [18] dan lahan gambut di Indonesia [19]. Emisi GRK akibat kerusakan hutan menyebabkan kesehatan paru-paru terganggu. Kementerian Kesehatan menyatakan dari Juni hingga pertengahan Oktober 2019 ada sebanyak 425.377 orang di tujuh provinsi terkena Infeksi Saluran Pernapasan Akut (ISPA) [20-21].

Indikator terjadinya kerusakan lingkungan [23] terutama yang berkaitan dengan sumber daya lahan, air, udara dan atmosfer sudah cukup nyata dan dirasakan oleh penduduk bumi [24]. Banjir tahunan yang semakin besar dan meluas, erosi dan pencemaran air sungai dan danau, tanah longsor dan kelangkaan air yang berakibat kelaparan di beberapa daerah dan negara di benua Asia, Afrika, dan Amerika Latin, merupakan realitas yang sudah, sedang, dan akan dirasakan oleh penduduk bumi [25- 
27]. Polusi air dan udara merupakan iklim yang mengakibatkan terjadinya musim hujan dan kemarau yang menyimpang, mencairnya salju di wilayah Kutup Utara dan Selatan [28] yang mengakibatkan naiknya permukaan air laut hingga menenggelamkan beberapa wilayah pantai dan pulau [29]. Kerusakan dan kepunahan spesies tumbuhan dan hewan [30], ledakan hama dan penyakit [31], serta krisis pangan dan energi [32] merupakan kejadian yang terkait erat dengan kerusakan lingkungan. Oleh karena itu, untuk menjaga keberlangsungan bumi termasuk kehidupan manusia penting dilakukan konservasi lingkungan hidup atau sumber daya alam. Apabila pemanfaatan sumber daya alam tidak diiringi dengan upaya konservasi, maka berbagai macam bahaya dapat mengancam kehidupan dan kelestarian bumi.

Secara umum konservasi memiliki arti memelihara atau menjaga sesuatu agar tetap ada [33]. Konservasi lekat hubungannya dengan upaya pelestarian sumber daya alam hayati, baik flora maupun fauna [34]. Menurut Undang-undang Republik Indonesia Nomor 5 Tahun 1990 [35], konservasi sumber daya alam hayati adalah pengelolaan sumber daya alam hayati yang pemanfaatannya dilakukan secara bijaksana untuk menjamin kesinambungan persediaannya dengan tetap memelihara dan meningkatkan kualitas keanekaragaman dan nilainya [36]. Konsevasi sumber daya alam merupakan upaya pengelolaan sumber daya alam secara bijaksana dengan berpedoman kepada azas pelestarian, pengelolaan terencana sumber daya alam sehingga terjadi berkelanjutan serta keseimbangan alami antara keanekaragaman dan proses perubahan evolusi dalam suatu lingkungan.

Dalam arti luas, konservasi adalah pemakaian dan perlindungan sumber daya. Sumber daya alam secara berkelanjutan meliputi tanaman (hutan), binatang, deposit-deposit mineral, tanah, air bersih, dan bahan bakar fosil seperti batu bara, petroleum, dan gas-gas alam (natural gas) [37-38]. Konservasi dari segi ekonomi dan ekologi, di mana konservasi dari segi ekonomi berarti mencoba mengalokasikan sumber daya alam untuk sekarang, sedangkan dari segi ekologi, konservasi merupakan alokasi sumber daya alam untuk sekarang dan masa yang akan datang. Dapat dikatakan pula konservasi alam adalah suatu manajemen terhadap alam dan lingkungan secara bijaksana untuk melindungi tanaman dan binatang.

Salah satu upaya konservasi lingkungan hidup adalah melalui pendidikan [39]. Pendidikan sangat penting dalam upaya membangun kesadaran akan pentingnya lingkungan hidup dan merupakan sebuah proses perjalanan yang dirintis demi keberlangsungan hidup generasi berikutnya agar tidak terancam akibat perilaku manusia yang tidak bertanggung jawab [40]. Pendidikan bukan sekedar proses transfer pengetahuan belaka, atau semata mengembangkan aspek intelektual, tetapi juga merupakan proses transformasi nilai dan pembentukkan karakter atau kepribadian dengan segala aspeknya [41]. Dengan proses semacam ini, maka suatu bangsa dapat mewariskan nilai-nilai keagamaan, kebudayaan, pemikiran dan keahlian pada generasi muda. Dengan kata lain, pendidikan adalah membangun budaya, membangun peradaban dan membangun masa depan bangsa. Pendidikan adalah daya upaya untuk memajukan budi pekerti, pikiran dan jasmani anak-anak, selaras dengan alam dan masyarakatnya.

\section{Hasil dan Pembahasan}

Sebagaimana pesan al-Quran dalam surah al-A'râf ayat 85, Islam meminta manusia untuk memanfaatkan alam, sekaligus mengecam manusia yang mengeksploitasi dan merusak alam [42]. Pesan al-Quran di atas sebenarnya demi kemaslahatan manusia itu sendiri karena pelestarian alam dan lingkungan berimplikasi positif terhadap kesejahteraan dan peningkatan taraf hidup manusia [43]. Kerahmatan semesta bisa terwujud bila mekanisme pengelolaan alam yang dilakukan manusia 
mengacu pada semangat keberagamaan yang mampu memberi kekuatan moral dalam mengubah pola hubungan manusia yang dominatif terhadap alam, menjadi lebih ramah, peduli, dan mencintai. AlQuran mengulang istilah tanah ( $a r d h)$ sebanyak 462 kali. Hal ini menunjukkan, betapa "tanah" menempati posisi penting dalam wacana Islam. Tanah tampil sebagai bagian sangat substantif dalam kehidupan, di samping manusia, tumbuhan, hewan, dan kehidupan lain [44]. Tanah yang ditumbuhi tanaman yang hijau menjadi citra kesuburan alam, keindahan lingkungan, dan kesejahteraan makhluk hidup. Penciptaan Adam dari tanah serta konsep khalîfah (QS. 6: 165) memberi petunjuk yang jelas bagaimana manusia dihimbau untuk memanfaatkan alam, tetapi harus disertai tanggung jawab pengelolaan dan pelestariannya (QS. 38: 27).

Islam memandang penataan lingkungan menjadi tanggung jawab manusia sebagai khalifah Allah di bumi. Tanggung jawab manusia terletak pada penataan, pemeliharaan, pengawasan dan pengembangan tata lingkungan yang bermanfaat bagi manusia. Tata lingkungan yang memberi manfaat besar bagi manusia terletak pada mekanisme kerja antara ekosistem dengan komunitas manusia. Jika mekanisme berjalan dengan baik, berarti manusia telah menempatkan diri pada posisi sebagai khalifah Allah di bumi [45]. Lingkungan yang sehat memberikan peluang bagi kelangsungan hidup ekosistem secara menyeluruh, sebaliknya lingkungan yang tercemar tidak akan mampu menunjang kelangsungan hidup secara menyeluruh . Oleh karena itu, menciptakan lingkungan hidup yang berdampak positif bagi kemakmuran dan kelangsungan hidup menjadi keharusan bagi manusia [46]. Agar manusia mampu menjadi khalifah atau sebagai pengemban fungsi penciptaan dan rububiyah-Nya terhadap lingkungan hidup, maka Allah telah menciptakan manusia dan menyiapkannya serta memberinya kelengkapan dan sarana yang diperlukan dengan sebaik-baiknya. Allah telah menciptakan manusia dengan struktur dasar penciptaan yang sebaik-baiknya. Allah juga telah memberikan bimbingan dan pengarahan kepada manusia agar ia mampu melaksanakan fungsi dan tugas hidupnya sebagai khalifah tersebut dengan sebaik-baiknya. Proses penciptaan dan pembimbingan manusia agar mampu melaksanakan tugas kekhalifahan di bumi ini, disebut sebagai proses dan fungsi rububiyah Allah terhadap manusia.

Dengan demikian, tugas kekhalifahan menuntut adanya interaksi antara manusia dengan sesamanya dan manusia dengan alam. Interaksi itu bersifat harmonis sesuai dengan petunjuk-petunjuk Ilahi yang tertera dalam wahyu-Nya. Inilah prinsip pokok yang merupakan landasan interaksi antara sesama manusia dan lingkungan sekitarnya dan keharmonisan hubungan itu pulalah yang menjadi tujuan dari segala etika agama.

Islam sebagai agama yang tidak hanya mengatur hubungan manusia dengan Khaliqnya, akan tetapi juga hubungan manusia dengan sesama makhluk, sesungguhnya telah memiliki landasan normatif baik secara implisit maupun eksplisit tentang menjaga dan melestarikan lingkungan hidup [47]. Misal, tentang tugas melestarikan lingkungan hidup yang merupakan manifestasi iman (QS. 7: 85), merusak lingkungan merupakan sifat orang-orang munafik (QS. 2: 205), alam semesta merupakan anugerah dari Allah untuk manusia (QS. 31: 20; QS. 14: 32-33), manusia adalah khalifah untuk menjaga kemakmuran lingkungan hidup (QS. 6: 165). Berangkat dari kenyataan tersebut, maka sesungguhnya disinilah peran dan fungsi penting kecerdasan akal manusia untuk melakukan kontekstualisasi ajaran Agama.

Suatu usaha yang didukung oleh infrastruktur pendidikan yang kondusif dan stabil dalam rangka pemberdayaan agama tersebut. Secara makro, pendidikan Islam mempunyai makna strategis sebagai institusi agama yang dapat menjalankan fungsi pokoknya untuk mensosialisasikan dan mentransformasikan nilai-nilai keagamaan dalam konteks dialektika kehidupan ini termasuk di 
dalamnya menanamkan kesadaran dalam pengelolaan lingkungan hidup. Oleh karena itu, untuk melihat peran pendidikan Islam dalam konservasi lingkungan hidup dapat dilihat dari tujuan pendidikan Islam [48] itu sendiri. Tujuan pendidikan Islam yang paling sederhana adalah memanusiakan manusia atau membantu manusia menjadi manusia. Pada hakekatnya tujuan pendidikan terfokus menjadi tiga bagian, yaitu: pertama, terbentuknya insan kamil atau manusia yang paripurna dengan kriteria insan yang beriman yang di dalam dirinya terdapat kekuatan, wawasan, perbuatan, kebijaksanaan dan mempunyai sifat sifat yang tercermin dalam pribadi Nabi Muhammad SAW berupa budi pekerti yang mulia. Kedua, terciptanya insan yang kaffah dalam dimensi agama, budaya dan ilmu. Dari dimensi agama, manusia merupakan makhluk yang memiliki berbagai macam dimensi, yaitu dimensi jasad dengan potensi al hayat; dimensi rohani dengan potensi spiritual (Ilahiyah) dan nafs dengan potensi qalbu, akal dan nafsu. Dari dimensi budaya manusia merupakan makhluk etis yang mempunyai kewajiban dan tanggung jawab terhadap kelestarian dunia seisinya. Pendidikan dipandang sebagai aktifitas yang memberikan suasana kondusif bagi pengembangan etos kultural manusia sehingga mampu berinteraksi dengan alam lingkungnanya [49]. Dari dimensi ilmu manusia akan senatiasa terdorong untuk bersikap secara objektif dan realistis dalam menghadapi tantangan zaman. Ketiga, adalah penyadaran manusia sebagai khalifah Allah di muka bumi.

Pendidikan Islam meletakkan kedudukan manusia sangat sentral sebagai subjek didik dalam upaya pembinaan dan pengembangannya. Proses pendidikan berusaha untuk melatih sensibilitas manusia sedemikian rupa sehingga dalam prilaku mereka terhadap kehidupan, langkah-langkah dan keputusan, begitu pula pendekatan terhadap ilmu pengetahuan diatur dan didasarkan pada nilai-nilai dan etika Islam. Sehingga tumbuh sebagai makhluk rasional, makhluk yang berbudi, bermoral dan spiritual dalam kehidupannya secara menyeluruh bagi kesejahteraan masyarakat dan umat manusia.

Proses pendidikan harus berupaya mengembangkan manusia agar memiliki pengetahuan , keterampilan, spiritual dan berfikir rasional, sehingga tumbuh perilaku manusia yang mencintai demokrasi, perdamaian, hidup selaras, stabil, berbudi dan berbudaya sebagai makhluk tuhan dan makhluk sosial yang hidup bersama manusia lain dengan tujuan memakmurkan, mengontrol dan mengatur alama semesta berdasarkan otoritas Tuhan. Artinya, proses pendidikan Islam akan menghasilkan manusia yang beramal dan berilmu ilahiyah sebagai manusia yang unggul. Dengan dasar ini, pengembangan konsep dasar pendidikan Islam harus bersumber dari konsep ilahiyah, konsep insaniyah dan konsep lingkungan yang integratif dan seimbang. Maka, dari sini posisi dan peran pendidikan Islam sangat sentral dalam memberdayakan dan mengaktualisasikan potensi fitrah melalui pendidikan sehingga memperoleh ilmu pengetahuan, teknologi, keterampilan, seni dan budaya berdasarkan nilai-nilai ilahiyah.

Pelaksanaan pendidikan Islam menempati posisi yang sangat urgent dan strategis dalam menciptakan situasi dan kondisi masyarakat yang sejahtera, adil dan makmur, serta lingkungan yang sehat, karena pendidikan Islam akan membimbing manusia dengan bimbingan wahyu Ilahi, sehingga terbentuk individu-individu yang memilki kepribadian yang islami. Pendidiakan Islam memfasilitasi manusia untuk belajar dan berlatih mengaktualisasikan segenap potensi yang dimilikinya, baik yang bersifat fisik maupun non fisik yang profilnya digambarkan Allah dalam al-Quran sebagai sosok ulil albab (QS. : 190-191) yaitu manusia yang berzikir sekaligus berpikir, berpikir dan berzikir disertai dengan sifat produktif dalam mengerjakan amal saleh di manapun ia berada.

Manusia sebagai bentuk tanggung jawabnya ikut serta dalam konservasi lingkungan hidup tidak terlepas dari fungsi dan tugas manusia menurut al-Quran. Dengan memerhatikan surat al-Mukminun ayat 115, manusia adalah makhluk yang fungsional dan bertanggung jawab. Artinya, manusia 
berfungsi terhadap pribadinya, berfungsi terhadap masyarakat, berfungsi terhadap lingkungan, dan berfungsi terhadap Allah Sang Pencipta Manusia.

Dalam menjalankan fungsinya terhadap lingkungan adalah bagaimana manusia memanfaatkan potensi alam untuk mencukupkan kebutuhan hidupnya [50]. Al-Quran menegaskan bahwa segala sesuatu di langit dan di bumi ditundukkan oleh Allah untuk memenuhi kebutuhan hidup manusia sendiri (QS. 45: 3). Laut, sungai, matahari, bulan, siang dan malam dijadikan sebagai sarana kemakmuran hidup manusia (QS. 14: 42-34). Binatang ternak diciptakan Allah untuk memenuhi kebutuhan hidup manusia (QS. 16: 5) Laut ditundukkan kepada manusia sebagai sarana komunikasi dan untuk digali dan dimanfaatkan kekayaannya (QS. 35: 12; QS. 16: 14). Manusia diwajibkan mengolah dan menjaga potensi alam untuk memenuhi kebutuhan hidupnya, dan ini merupakan tuntutan fungsi manusia terhadap alam [51]. Oleh karena itu, dalam menjaga dan mengolah potensi alam merupakan fardhu kifayah, karena tidak semua manusia mempunyai kemampuan untuk menggali potensi alam yang diberikan tersebut. Untuk itu, apabila manusia menyia-nyiakan dan merusak potensi alam berarti mengabaikan potensi manusia terhadap alamnya atau bahkan telah kufur nikmat.

Dalam memenuhi fungsi manusia terhadap alam, hendaknya selalu diusahakan agar ekosistem alam tidak terganggu, tidak memanfaatkan potensi alam secara berlebihan, agar generasi mendatang masih dapat menikmatinya, karena potensi alam terbatas. Apabila berlaku berlebih-lebihan, tamak, dan rakus dalam memanfaatkan potensi alam akan berakibat kerusakan pada manusia itu sendiri. Dalam konteks ini, Allah memperingatkan manusia (QS. 30: 41) bahwa kerusakan di darat dan laut terjadi akibat perbuatan tangan manusia itu sendiri: Allah merasakan kepada mereka sebagai akibat perbuatan mereka, supaya mereka kembali ke jalan yang benar. Berdasarkan ayat tersebut, kita harus memerhatikan kepentingan generasi mendatang dengan berusaha menjaga, melestarikan potensi alam untuk kepentingan manusia.

\section{Kesimpulan}

Penelitian ini menyimpulkan bahwa agama Islam merupakan sumber inspirasi moralitas dan spiritualitas yang menjadi sebuah kebutuhan peradaban kontemporer. Keterlibatan agama Islam dalam konservasi lingkungan dan penyelamatan kerusakan bumi menjadi tidak terelakkan. Salah satu tujuan pemahaman Islam multidimensional yang bisa mengintegrasikan secara proporsional antara dimensi spiritual dan rasionalitas serta wawasan kosmetik dan humanistik secara bersamaan menjadi opsi yang menjanjikan untuk mengatasi krisis lingkungan melalui pendidikan Islam. Konservasi lingkungan melalui pendidikan Islam diharapkan dapat memberikan kesempatan bagi setiap individu untuk memperoleh pengertian dasar tentang lingkungan hidup, permasalahannya serta peran dan tanggung jawab manusia dalam melestarikan fungsi-fungsi lingkungan hidup.

\section{Referensi}

[1] M. Choudhary, C. N. Peter, S. K. Shukla, P. P. Govender, G. M. Joshi, \& R. Wang 2020 Environmental issues: A challenge for wastewater treatment In Green Materials for Wastewater Treatment. Springer, Cham. 1-12

[2] T. Cüre, E. Esen, \& A. Özsözgün Çalışkan 2020 Impression management in graphical representation of economic, social, and environmental issues: An empirical study Sustainability. 121379

[3] S. N. Longinos, D. D. Longinou, \& S. Achinas 2020 Natural gas hydrates: Possible environmental issues In Contemporary Environmental Issues and Challenges in Era of Climate Change. Springer, Singapore. 277-293 
[4] C. Sonne, R. Dietz, \& A. K. Alstrup 2020 Factors affecting global flow of scientific knowledge in environmental sciences Science of the Total Environment. 701135012

[5] J. Zaini, A. D. Susanto, E. Samoedro, V. C. Bionika, \& B. Antariksa 2020 Health consequences of thick forest fire smoke to healthy residents in Riau, Indonesia: a cross-sectional study Medical Journal of Indonesia. 291 58-63

[6] R. Pramudya 2020 Elaboration of forest management aspect in Indonesia's forestry legal perspective JL Pol'y \& Globalization. 9345

[7] K. H. Cook, Y. Liu, \& E. K. Vizy 2020 Congo Basin drying associated with poleward shifts of the African thermal lows Climate Dynamics. 54 1-2 863-883

[8] N. L. Celli, S. Lebedev, A. J. Schaeffer, M. Ravenna, \& C. Gaina 2020 The upper mantle beneath the South Atlantic Ocean, South America and Africa from waveform tomography with massive data sets Geophysical Journal International. 2211 178-204

[9] C. Lorenzo, \& J. H. González 2020 The global environment facility and Latin American countries In Latin America in Times of Global Environmental Change. Springer, Cham. 1-14

[10] R. B. Edwards, R. L. Naylor, M. M. Higgins, \& W. P. Falcon 2020 Causes of Indonesia's forest fires World Development. 127104717

[11] H. A. Rachman, J. L. Gaol, F. Syamsudin, \& A. As-syakur 2020 Influence of coastal upwelling on sea surface temperature trends Banda Sea. In IOP Conference Series: Earth and Environmental Science. IOP Publishing. 4291012015

[12] A. M. Fahmita, R. Azizah, M. E. Kurniadi, \& J. Jalaludin 2020 Analysis of PM2. 5 cement dust levels, temperature and humidity in limestone burning home industry Tuban Regency, East Java, Indonesia International Journal of Psychosocial Rehabilitation. 241

[13] J. van de Haterd, B. Budiyono, Y. H. Darundiati, \& E. Spaan 2020 Environmental change and health risks in coastal Semarang, Indonesia: Importance of local indigenous knowledge for strengthening adaptation policies Cities \& Health. 1-13

[14] C. K. Tito, \& E. E. Ampou 2020 Coral reefs ecosystem degradation at Nusa Penida, Bali In IOP Conference Series: Earth and Environmental Science. IOP Publishing. 4291012053

[15] H. H. Madduppa, A. F. Koropitan, A. Damar, B. Subhan, M. Taufik, A. A. Taurusman, \& A. B. Purwanto 2020 Ecological vulnerability of coral reef ecosystem in Wakatobi National Park during Indian ocean dipole event HAYATI Journal of Biosciences. 27 157-57

[16] H. Tamsah, \& N. Nessa 2019 The application of economic-valuation in the calculation of damage to coral reefs ecosystems in Indonesia In IOP Conference Series: Earth and Environmental Science. IOP Publishing. 2351012096

[17] F. M. França, C. E. Benkwitt, G. Peralta, J. P. Robinson, N. A. Graham, J. M. Tylianakis, \& J. Barlow 2020 Climatic and local stressor interactions threaten tropical forests and coral reefs Philosophical Transactions of the Royal Society B. 375179420190116

[18] E. Meijaard, T. Santika, K. A. Wilson, S. Budiharta, A. Kusworo, E. A. Law, \& F. A. S. John 2020 Toward improved impact evaluation of community forest management in Indonesia Conservation Science and Practice.

[19] Y. Yamamoto, K. Takeuchi, \& G. Köhlin 2020 Preventing peatland fires in Central Kalimantan, Indonesia: The role of economic incentives and social norms. Journal of Forest Economics. 35 2-3 207-227

[20] L. Maria, M. Simanjuntak, T. Silangit, \& J. M. Siahaan 2020 Determinants of acute respiratory infection in children under five in Simalingkar, Medan, North Sumatera Journal of Epidemiology and Public Health. 51 26-30

[21] S. Krisnasari, D. Trisha, R. Nur, R. D. Larasati, \& E. Mantao 2019 Mother's behavior in treating of acute respiratory infections on children post the earthquake and tsunami disaster at the public health center in Wani, Donggala, Central of Sulawesi, Indonesia American Journal of Biological and Environmental Statistics. 5 73-77 
[22] R. M. Deus, F. D. Mele, B. S. Bezerra, \& R. A. G. Battistelle 2020 A municipal solid waste indicator for environmental impact: Assessment and identification of best management practices. Journal of Cleaner Production. 242118433

[23] A. López-Sánchez, R. Perea, S. Roig, J. Isselstein, \& A. Schmitz 2020 Challenges on the conservation of traditional orchards: Tree damage as an indicator of sustainable grazing Journal of Environmental Management. 257110010

[24] J. M. Otaki 2020 The pale grass blue butterfly as an indicator for the biological effect of the Fukushima Daiichi Nuclear power plant accident In Low-Dose Radiation Effects on Animals and Ecosystems. Springer, Singapore. 239-247

[25] E. Goretti, M. Pallottini, S. Pagliarini, M. Catasti, G. La Porta, R. Selvaggi, \& A. Ali 2020 Use of larval morphological deformities in chironomus plumosus (chironomidae: diptera) as an indicator of freshwater environmental contamination (Lake Trasimeno, Italy) Water. 1211

[26] S. Saud, S. Chen, \& A. Haseeb 2020 The role of financial development and globalization in the environment: Accounting ecological footprint indicators for selected one-belt-one-road initiative countries Journal of Cleaner Production. 250119518

[27] S. G. Tyaglov, M. A. Ponomareva, V. B. \& Cheremina 2020 Remediation measures for accumulated environmental damages using principles of sustainable development: A case study of Russian regions In Sustainability Perspectives: Science, Policy and Practice. Springer, Cham. 119-131

[28] A. Kennedy, \& C. Jones 2020 GOES-16 observations of blowing snow in horizontal convective rolls on 24 February 2019 Monthly Weather Review. 1484 1737-1750

[29] X. Li, T. Che, X. Li, L. Wang, A. Duan, D. Shangguan, \& Q. Bao 2020 CASEarth poles: Big data for the three poles Bulletin of the American Meteorological Society.

[30] Y. Güllüce, \& R. N. Çelik 2020 FireAnalyst: An effective system for detecting fire geolocation and fire behavior in forests using mathematical modeling Turkish Journal of Agriculture and Forestry. 44 127-139

[31] G. Martínez 2020 Biological control of forest pests in Uruguay. In Forest Pest and Disease Management in Latin America. Springer, Cham. 7-30

[32] C. Dorninger, D. J. Abson, C. I. Apetrei, P. Derwort, C. D. Ives, K. Klaniecki, \& H. von Wehrden 2020 Leverage points for sustainability transformation: a review on interventions in food and energy systems Ecological Economics. 171106570

[33] M. S. Jones, T. L.Teel, D. E. Martinez, \& J. Solomon 2020 Conflict and adaptation at the intersection of motherhood and conservation leadership Biological Conservation. 243108487

[34] B. Okumu, \& E. Muchapondwa 2020 Welfare and forest cover impacts of incentive based conservation: Evidence from Kenyan community forest associations World Development. 129 104890

[35] I. G. B. Suryawan, \& I. Aris 2020 Strengthening environmental law policy and its influence on environmental sustainability performance: Empirical studies of green constitution in adopting countries International Journal of Energy Economics and Policy. 102 132-138

[36] A. Sahri, P. L. K. Mustika, H. Y. Dewanto, \& A. J. Murk 2020 A critical review of marine mammal governance and protection in Indonesia Marine Policy. 103893

[37] V. K. Bisch, V. S. Quaresma, J. B. Teixeira, \& A. C. Bastos 2020 Using GIS to map priority areas for conservation versus mineral exploration: Territorial sea of Espírito Santo State, Brazil, study case In International Business, Trade and Institutional Sustainability. Springer, Cham. 677-689

[38] K. J. Wallace, M. K. Kim, A. Rogers, \& M. Jago 2020 Classifying human wellbeing values for planning the conservation and use of natural resources Journal of Environmental Management. 256109955

[39] S. Kuraedah, F. Gunawan, I. S. Wekke, \& B. Hamuddin 2018 Learning environment construction in Islamic Higher Education: Connecting the puzzles of ideas In IOP Conference Series: Earth and Environmental Science. IOP Publishing. 1751012107 
[40] C. R. Clark, J. E. Heimlich, N. M. Ardoin, \& J. Braus 2020 Using a Delphi study to clarify the landscape and core outcomes in environmental education. Environmental Education Research. 263 381-399

[41] S. L. Brown, L. Siegel, \& S. M. Blom 2020 Entanglements of matter and meaning: The importance of the philosophy of Karen Barad for environmental education Australian Journal of Environmental Education. 1-15

[42] F. Zagonari 2020 Comparing religious environmental ethics to support efforts to achieve local and global sustainability: empirical insights based on a theoretical framework Sustainability. 12 72590

[43] T. Ismawati 2020 Fostering environmental awareness at nurul asna islamic boarding school Journal of Islam and Science. 52

[44] R. Hancock 2020 Muslim environmentalists, activism, and religious duty. In Muslim Volunteering in the West. Palgrave Macmillan, Cham. 141-160

[45] J. La Fua, R. U. Nurlila, F. Gunawan, \& I. S. Wekke 2018 Islamic education on formation of environmental awareness in Indonesian Islamic Boarding Schools In IOP Conference Series: Earth and Environmental Science. IOP Publishing. 1561012035

[46] H. Azemati, \& A. S. Habibabad 2020 Explaining an influential model of the significant relationship between religion, spirituality, and environmental peace in Mosque interior architecture Journal of Religion and Health. 1-14

[47] M. S. Abdullah, \& J. S. Keshminder 2020 Religion and pro-environmental behaviour: a comparative analysis towards environmental protection International Journal of Environment and Sustainable Development. 192 174-194

[48] K. T. Phuah, M. W. Ow, S. K. Sandhu, \& U. K. Kassim 2020 Green attitude and purchase intention towards environmental friendly product Journal Of Emerging Economies and Islamic Research. 61 17-25

[49] I. S. Wekke, \& S. Mokodenseho 2017 Religious teaching and learning in minority Muslim of Manado Indonesia In 2nd International Conference on Education, Science, and Technology (ICEST 2017). Atlantis Press.

[50] A. Andriansyah, T. Taufiqurokhman, \& I. S. Wekke 2019 Impact of environmental policy factors on tourism industry: A study from Indonesia over last three decades International Journal of Energy Economics and Policy. 93360

[51] K. Singh 2020 Tracing environmental ethics in the HolyQur'an Studies in Indian Place Names. $4011519-1523$ 